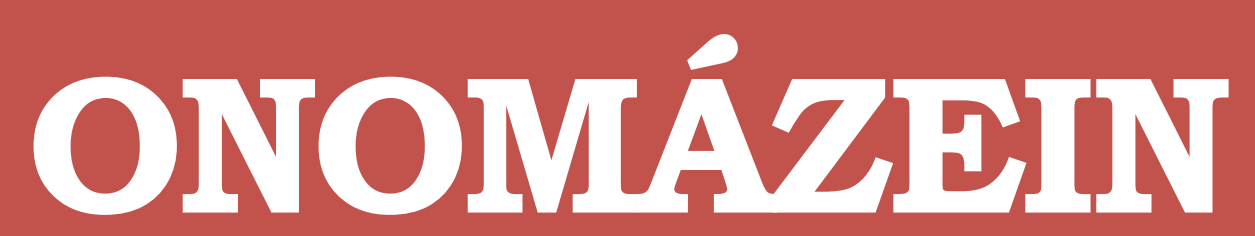

Journal of linguistics, philology and translation
PONTIFICIA UNIVERSIDAD

\title{
A study of contextual vowel nasalization in standard peninsular Spanish
}

\author{
Ana Ma. Fernández Planas \\ Universitat de Barcelona \\ España
}

ONOMÁZEIN 49 (September 2020): 225-256

DOI: 10.7764/onomazein.49.11

ISSN: 0718-5758

\section{(C) $($ (i) $\ominus$}

Ana Ma. Fernández Planas: Laboratori de Fonètica, Universitat de Barcelona, España.

| E-mail: anamariafernandez@ub.edu 


\section{Abstract}

Since Navarro Tomás (1918) it is well known in Spanish phonetics that vowels between nasals become nasalized and that vowels followed by a nasal in syllable coda position might undergo a certain degree of nasalization, even if Spanish does not have nasal vowels from the phonological point of view. This study aims to explore this phenomenon through the use of a Nasometer by examining several nasal-vowel contexts ( $N V$, VN, and NVN sequences, and with post-vocalic nasals in tautosyllabic or heterosyllabic sequences with reference to the preceding vowel), the distinction between stressed and unstressed syllables containing the target vowel, and three speaking rate conditions (slow, normal, and fast). The utterances produced by three speakers of standard peninsular Spanish are analyzed. Results of the percentage of nasality and nasalance indicate that the variables under examination are statistically significant in the process of vowel nasalization, though to a varying extent. A closer look at the different syllable positions in the nasal-vowel relationship addresses the issue of anticipatory vs. carryover coarticulation effects on vowel nasalization.

Keywords: nasality; nasalance; Nasometer; coarticulation; standard peninsular Spanish. 


\section{Introduction}

The mechanism responsible for the articulatory production of the universal phenomenon of nasalization involves the relaxation of the levator palatini muscle, although in some instances the palatoglossus muscle might also take part (Bell-Berti, 1973, 1976, 1993; Bell-Berti \& Hirose, 1973; Bell-Berti et al., 1979; Marchal, 2009). According to Bell-Berti (1993: 64), several studies have shown that the velum can take more than two positions, ranging from the lowest position-i.e., that of nasals - to the highest position in oral sounds. Therefore, in nasalized vowels the velum would take an intermediate position.

As the opening and the closing of the velum are independent of the movements of the oral articulators and of the vocal fold action, it could be argued that several positions of the velum might occur simultaneously at different articulatory constrictions and glottal actions. However, as Solé (2007: 261) points out, this does not happen in the world's languages. There exist interaction or dependency relationships among the articulatory gestures-or their acoustic consequences-mainly due to aerodynamic requirements. Ohala and Ohala (1993) illustrate how acoustic and aerodynamic factors of nasals interact with other features, in particular, place and manner of articulation. Additionally, Ohala (1976) reviews the most frequently occurring synchronic and diachronic phonological processes in the world's languages and relates them to the phonetic requirements involved in the production and perception of nasal vowels and nasal consonants, in addition to proposing the construction of an aerodynamic model of speech production.

Nasalization processes constitute a good study case in order to investigate the relationship between phonetic requirements and phonological models. Definitely, research on nasals has greatly contributed to the development of theories and coarticulation models(Farnetani\& Recasens, 1999). For instance, Hajek (1997) investigated the universals of sound change in nasalization and reported on the convergences between these universals and the general mechanisms of speech production and perception.

Given that the characteristics of vowels are determined by tongue height and frontness and, also, lip rounding, the passage of airflow through the nasal cavity can occur simultaneously thanks to the coproduction of adjacent nasals without affecting vowel timbre. For that reason, vowels can become nasalized. In these nasalized vowels, the airflow is a combination of energy exiting through the nose and the mouth. The airflow released through the mouth will be dominant when the area of oral constriction is larger than the area of velopharyngeal opening of approximately $20 \mathrm{~mm}^{2}$ (Stevens, 1998).

In some languages like French, Portuguese ${ }^{1}$, Yoruba, and Polish, there are oral and nasal vowels that contrast phonologically, while in other languages like Spanish vowel nasalization is not phonological. Navarro Tomás (1985 [1918]: 39) indicates that in Spanish

1 It should be noted that authors do not agree on the phonological distinction between oral and nasal vowels in Portuguese. Some phonologists, among them Morais Barbosa (1962) and Mira Mateus and 
A veces la consonante final de sílaba influye sobre la vocal precedente, nasalizándola en más o menos parte; pero dicha consonante, aunque en muchos casos resulte relajada, pocas veces Ilega a perder, como en francés, su propia articulación. Una vocal entre dos consonantes nasales resulta, en general, completamente nasalizada [...] En posición inicial absoluta, seguida de m o n, también es frecuente la nasalización de la vocal.

Sometimes the consonant in syllable-final position influences the preceding vowel, by nasalizing it to a greater or lesser extent; but this consonant, even if realized as a lenis consonant in many instances, rarely loses its own articulation, as is the case of French. A vowel between two nasal consonants frequently undergoes full nasalization [...] In absolute utterance-initial position, the nasalization of a vowel followed by [m] or [ $\mathrm{n}$ ] is also quite common. [author's own translation]

Obediente (2007: 111) states that nasalized vowels in Spanish no tienen función lingüística distintiva, su ligera resonancia nasal se debe al entorno fónico o a hábitos individuales ["do not have a distinctive linguistic function, their light nasal resonance derives from the phonetic context or individual practices"]. However, he does not specify which phonetic contexts favour coarticulation.

Despite these accounts, to date vowel nasalization in Spanish has not been tackled in great detail in phonetic manuals. As Regueira (2010: 74) recently pointed out in his article published in the journal Estudios de Fonética Experimental,

la nasalización de los sonidos vocálicos adyacentes a las sonantes nasales, habitualmente recibe poca atención en las lenguas que, como el gallego y el castellano, no presentan nasalidad contrastiva en el sistema vocálico, yen general suele despacharse con unas pocas frases en las gramáticas o en las fonéticas descriptivas.

nasalization of vowel sounds adjacent to nasal sonorants has typically received little attention in languages that do not have contrastive nasality in their vowel system, such as Galician and Spanish, and is usually summarized in very few sentences in grammar and descriptive phonetics books. [author's own translation]

In contrast, there is plenty of work on the general aerodynamic mechanisms that these articulations require (such as work by Ohala and Solé) as well as clinical studies using the Nasometer to complement the data collected on patients or control speakers. The latter studies, which have examined both adults and children, measure the average nasalance in sentences containing nasals and sentences without nasals. At present normative values are available for several languages, among others, English, French, Thai, Flemish, Hungarian, Spanish, Portuguese, Finnish, Swedish, Cantonese Chinese, and Japanese (Haapanen, 1991; Seaver et al.,

D’Andrade (2000), state that Portuguese does not have phonological nasal vowels. Instead, they indicate that this language has nasal vowels in their phonetic realization, which do indeed contrast with oral vowels, but from the phonological point of view they should be considered as VN sequences. 
1991; Leeper, Rochet \& MacKay, 1992; Kavanagh et al., 1994; Rochet, Rochet, Sovis \& Mielke, 1998; van Doorn \& Purcell, 1998; Tachimura et al., 2000; Whitehill, 2001; van Lierde et al., 2002; Prathanee et al., 2003; Sweeney, Sell \& O’Regan, 2004; Mishima et al., 2008; Brunnegard \& van Doorn, 2009; Mattiolli, 2007). However, from a linguistic point of view, the type of analysis of the studies listed above is not relevant to this paper as its main objective is to provide a full account of phonetic details in speakers without any articulatory disorders.

Phonologically speaking, nasalization is a binary feature (presence vs. absence), but from a phonetic perspective nasalization is a complex feature. Both in languages that include nasal vowels and those languages that do not, vowels have an oral variety, a lightly nasalized variety, and a heavily nasalized variety. (See Figure 1 for an example of the phonetic distinction between the three types of nasalization in French.)

\section{FIGURE 1}

Nasal airflow curves in French sequences: bonnet ('hat'), nonnette ('nap'), and non-être ('not be'). From left to right, the sequences correspond to an oral vowel, a contextually nasalized vowel, and a nasal vowel or phonologically nasalized vowel, respectively. (Adapted from Ladefoged \& Maddieson, 1996: 299)

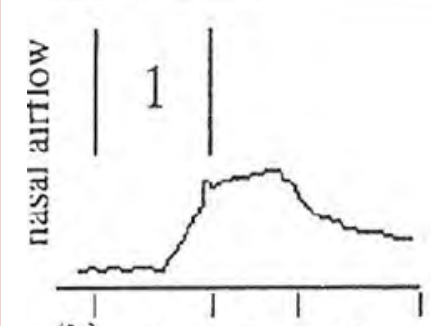

(b) 0

n

$\varepsilon$

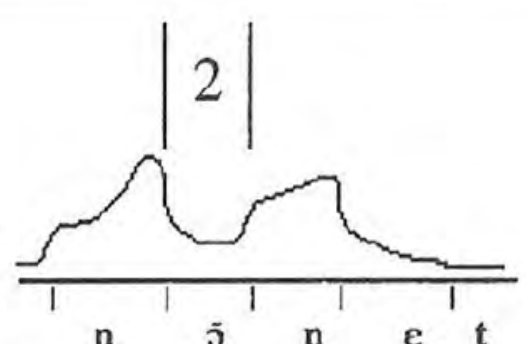

n

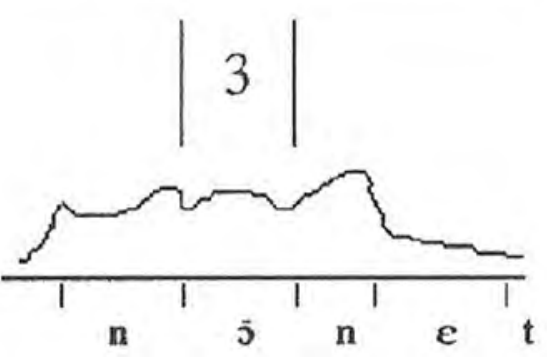

n

Therefore, at the phonetic level differences in the degree of nasalization of vowels adjacent to nasals must be established. These differences entail a variation in the degree of velar elevation, although the articulatory difference can be barely discerned acoustically and/or auditorily. Ladefoged and Maddieson (1996: 298-299) state that

Nasalization appears to be a binary feature from a phonological point of view. But there are surface phonetic contrasts between oral, lightly nasalized, and heavily nasalized vowels in some languages. This usually occurs when a language with a phonological contrast between oral and nasalized vowels in addition has oral vowels that are contextually nasalized vowels when adjacent to a nasal consonant [...] Auditory and acoustic analysis of such items show clear differences between the two types of nasalized vowels in the relative timing of the onset and offset of nasality. The vowels that were described as lightly nasalized are in fact audibly nasalized through only the latter part of their duration.

The authors refer to light and heavy nasalization in those languages that contain contrastively distinct oral and nasal vowels. While Spanish is not part of this group of languages, it 
also appears to present variations in the degree of nasalization depending on the syllabic relationship between the vowel and neighbouring nasals.

The aim of this study is to examine the characteristics of the phenomenon of contextual phonetic nasalization in Spanish. Specifically, this paper explores the effects of adjacent nasals on the oral vowel and whether there are different degrees of nasalization. It also intends to determine whether nasalization involves distinct individual traits and whether it is affected by speaking rate, syllable stress position, and the syllabic relationship between the vowel and adjacent nasals.

It should be mentioned that even though the degree of velopharyngeal port opening cannot be measured articulatorily in a direct manner, it is possible to infer instances of heavier or lighter nasalization from parameters such as nasality and nasalance. Furthermore, while nasality and nasalance refer to two related aspects, in this paper they are not used interchangeably. Rather, they are considered as two parameters that relate to nasalization. That is, "nasality" refers to the acoustic signal that is clearly displayed on a waveform-or the duration of nasal airflow that segments exhibit-in contrast to other accounts defining "nasality" as the auditory outcome of voice quality (e.g., Baken \& Orlikoff, 2000). On the other hand, "nasalance" refers to the articulatory parameter that indicates the amount of nasal airflow. The term "nasalance" was first proposed by Fletcher and Frost (1974) as a measure of velopharyngeal port closure during voiced speech or, in other words, as a measure of nasal energy produced by the nose in a similar way to the energy produced by the oral passage. Nasalance can be calculated as the ratio between nasal airflow and oral airflow. It can also be reported in percentages, as in the present study. In both cases, the resulting nasalance scores include the same information, though on a different scale.

\section{Method}

The organ responsible for the distinction between oral and nasal sounds is the soft palate or velum, which is placed against the pharyngeal wall for the production of oral sounds and which lowers in the case of nasal sounds. While it is possible to observe the movement of the velum in clinical environments through specific instrumentation, it cannot be easily examined in a direct way and it is difficult to access in phonetic laboratories. In relation to this, Rossato, Badin \& Bouaouni (2003: 3141-3142) point out that

The oral and nasal vowels are clearly separated: the oral vowels are produced with a velum height between $10.4 \mathrm{~cm}$ and $10.8 \mathrm{~cm}$ (mean $10.66 \mathrm{~cm}$ ), whereas the nasal vowels are realised with a velum height between $9.8 \mathrm{~cm}$ and $10.2 \mathrm{~cm}$ (mean $9.96 \mathrm{~cm}$ ). Most of the oral consonants are produced with a velum height about $10.7 \mathrm{~cm}$. [...] It is worthy of note that there exists a velum height range (10.4 $-10.65 \mathrm{~cm}$ ) in which both oral vowels and nasal consonants are produced: the precise control of velum would not be necessary to produce sequences such as [mama]. 
As noted above, it is possible to infer the movement of the velum indirectly by measuring the amount of nasal airflow, which will be necessarily greater if the velum is lowered so that the airflow can exit through the nasal passage. In the production of nasal and nasalized vowels - with a velum height that cannot be different from that of nasal consonants in some cases, as Rossato, Badin, and Bouaouni (2003) indicate-these sounds are emitted through the vocal tract partly through the oral cavity and partly through the nasal cavity. Nasal airflow can then be measured phonetically by means of a Nasometer. This technique is used even in clinical studies to complement the direct method of observing the velopharyngeal function (van Lierde et al., 2002).

For this study, the Kay Nasometer II 6400 (Kay Elemetrics, 2001) and CSL4500 (Kay Elemetrics, 2004) were used. Prior to recording each of the speakers, the Nasometer was calibrated according to the manual's instructions. Although there are other available systems to assess nasalance aspects, the Nasometer has been utilized most frequently as it is relatively easy to operate and it yields reliable and valid data (Mishima et al., 2008). The Nasometer consists of a structure that collects oral and nasal airflow from two directional microphones, one placed in front of the speaker's mouth and the other in front of the speaker's nose, which are separated from each other by a thin metal plate. As seen in Figure 2, the headset device worn by the speaker is held by a harness. This tool is a non-invasive method for the speaker and it allows researchers to analyze nasalance. On the other hand, Kay CSL4500 was used to analyze the data acoustically as the two independent and physically separated microphones attached to the Nasometer gather output data in a different channel, which makes it possible to test the synchronization between the nasal source and the oral source in order to study nasality (Fletcher, 1970).

\section{FIGURE 2}

Picture of a speaker about to record his voice with a Nasometer. Note the two microphones separated by a plate and inserted into a frame held round the speaker's head with a harness

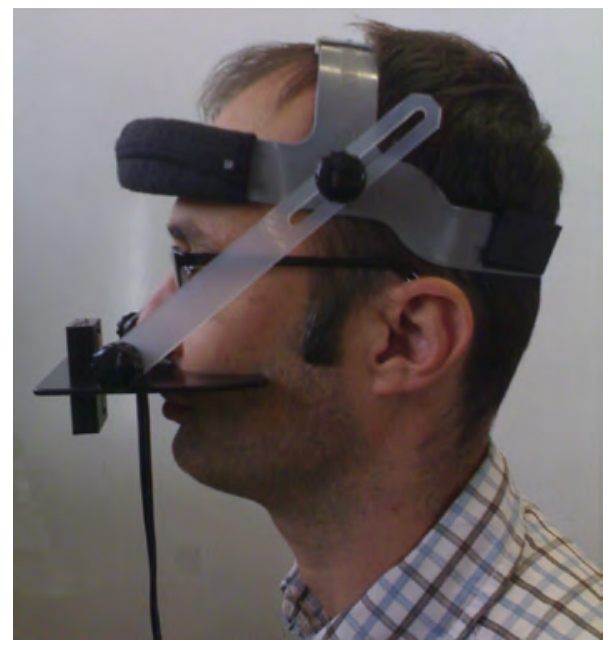


For the present study, the production of three speakers - two males, EMC and LXG, and one female, AFP — was analyzed. The speakers were adult native speakers of the Spanish of Catalonia, all with university degrees. None of the speakers had any disorder in their supraglottal cavities.

The speakers were asked to read a number of words in the carrier sentence Diga todavía ('Say still') three times (not in a row) at different speaking rates in the Laboratori de Fonètica of the Universitat de Barcelona (UB), Spain. Three speaking rates were considered: normal (or speaking rate that was most comfortable for each speaker), intentionally slower, and deliberately faster. Table 1 below displays the words included in the corpus of the study, which amounted to a total of 1620 words (60 words $\times 3$ times $\times 3$ speaking rates $\times 3$ speakers). As can be seen in this table, and based on several articulatory studies (e.g., Clumeck, 1976; Bell-Berti, 1976; Kolia et al., 1995; Kuehn \& Moon, 1998; Rossato, Badin \& Bouaouni, 2003), the low vowel [a] was the target sound since it is produced with greater velum lowering than that of high vowels. Moreover, these studies demonstrate that velum height not only correlates with tongue and mandible height, but also that the coarticulatory gestures between the velum and the other articulators are linked through timing patterns among the gestures involved.

\section{TABLE 1}

Classification of the words comprising the corpus of the study

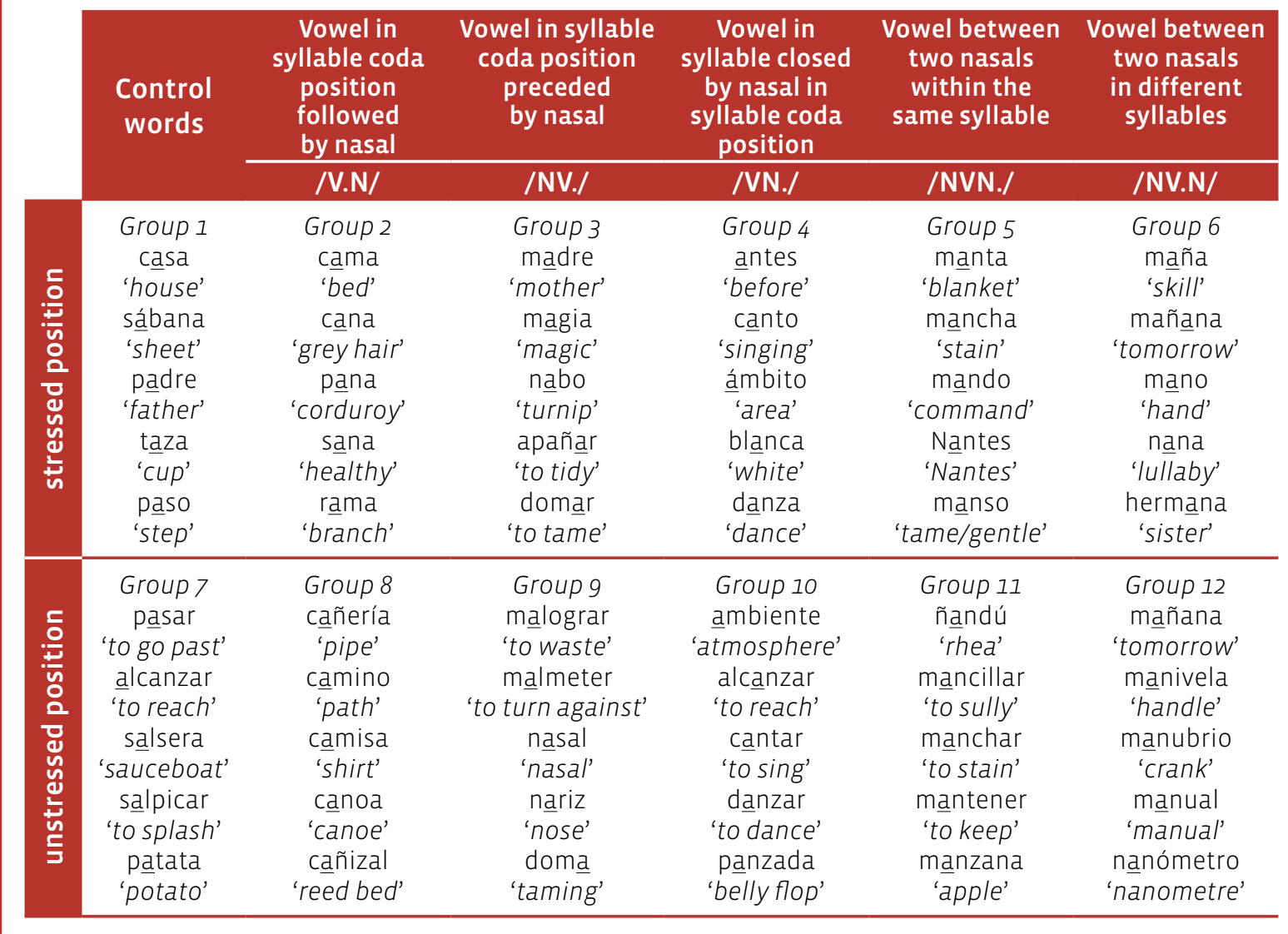


The independent variables of the study were speaker, speaking rate, stress position, and syllabic relationship between the vowel and adjacent nasals. The dependent variables consisted of the percentage of nasality in the vowel (computed on the relation between total vowel duration and duration of the acoustic trace of nasality in the target vowel) and the percentage of nasalance (nasal to oral airflow ratio) in the vowel. Statistical analyses-namely, ANOVAs and Scheffé post-hoc tests-were performed on PASW 17.0.2.

\section{Results}

When the factor of speaker was considered, the ANOVA conducted yielded many significant differences in the three speaking rates and in the phonic groups under investigation $(p<.05)$. Consequently, the results observed for each speaker will be reported separately. In this regard, much research into both normal speaking and clinical populations has also found relevant inter-speaker differences in nasalance, e.g., as a function of age² (Haapanen, 1991; Anderson, 19963; van Lierde et al., 2003; Hirschberg et al., 2006), gender (van Lierde et al., 2001; Prathanee et al., 2003), languages and dialects (Seaver et al., 1991; Leeper et al., 1992; Nichols, 1999; van Lierde et al., 2001), or even as a function of bilinguals speaking one language or another (Leeper et al., 19924). However, other studies point to the contrary, that is, a lack of significant results as a function of age (van Doorn \& Purcell, 1998), gender (Brunnegard \& van Doorn, 2009; Litzaw \& Dalston, 1992; van Doorn \& Purcell, 1998; Kavanagh et al., 1994; Nichols, 1999; Sweeney et al., 2004; Zajac, Mayo \& Kataoka, 1998), or different dialects (Brunnegard \& van Doorn, 2009; Kavanagh et al., 1994; Mishima et al., 2008).

Concerning speaking rate, the values obtained for each of the three speakers are displayed in Table 2 below, where three different trends among the speakers can be observed. In the first place, speaker AFP's values show that as speaking rate increases, so does the percentage of nasality and nasalance in the vowel. Moreover, the difference in nasalance scores was significant between slow and fast speaking rates $(p=.000)$ and between slow and normal speaking rates $(p=.007)$. Secondly, speaker EMC barely exhibits any differences in nasality scores as a result of various speaking rates, while nasalance scores are lower at a normal speaking rate. Despite this, the statistical analyses conducted did not yield any significant differences, which indicated that this speaker's speech is not particularly influenced by speaking rate. Finally, speaker XLG's nasality scores decrease as speaking rate increases, which results in statistically significant differences ( $p=.003$ ) - more specifically, between slow and normal speaking rates $(p=.033)$ and slow and fast speaking rates $(p=.006)$. By contrast, speaking rate has hardly any effect on the percentage of nasalance.

2 Age differences are particularly observed in those studies examining child and adult speech.

3 This investigation found significant differences among Puerto Rican Spanish speakers.

4 This study also showed a high degree of inter-speaker variability. 


\section{TABLE 2}

Mean and standard deviation values of nasality and nasalance as a function of speaking rate

\begin{tabular}{ccccccc}
$\begin{array}{c}\text { SPEAKING } \\
\text { RATE }\end{array}$ & \multicolumn{3}{c}{ \% OF NASALITY IN VOWEL } & \multicolumn{3}{c}{ \% OF NASALANCE IN VOWEL } \\
\cline { 2 - 7 } & AFP & EMC & XLG & AFP & EMC & XLG \\
\cline { 2 - 7 } & $\mathbf{M}$ (SD) & $\mathbf{M}($ SD) & M (SD) & M (SD) & M (SD) & M (SD) \\
\multirow{2}{*}{ Slow } & 72.48 & 76.87 & 81.01 & 43.79 & 53.54 & 60.20 \\
& $(36.54)$ & $(36.80)$ & $(32.32)$ & $(16.95)$ & $(17.92)$ & $(21.31)$ \\
\hline \multirow{2}{*}{ Normal } & 74.19 & 72.74 & 71.01 & 45.75 & 53.90 & 63.23 \\
& $(37.82)$ & $(35.16)$ & $(37.99)$ & $(17.72)$ & $(17.73)$ & $(22.16)$ \\
\hline \multirow{2}{*}{ Fast } & 78.51 & 78.01 & 68.75 & 51.92 & 53.12 & 62.74 \\
& $(37.24)$ & $(36.53)$ & $(38.24)$ & $(20.88)$ & $(19.31)$ & $(23.03)$ \\
\hline
\end{tabular}

Next, the effect of the stress position of the vowel examined with respect to the effect of the adjacent nasal on the vowel deserves some attention. Table 3 illustrates the mean nasality and nasalance scores as a function of speaking rate and stress position of the vowel under study.

\section{TABLE 3}

Mean and standard deviation values of nasality and nasalance as a function of speaking rate and stress position of the vowel under study

\begin{tabular}{|c|c|c|c|c|c|}
\hline \multirow[t]{2}{*}{ SPEAKER } & \multirow{2}{*}{$\begin{array}{c}\text { SPEAKING } \\
\text { RATE }\end{array}$} & \multicolumn{2}{|c|}{$\%$ OF NASALITY IN VOWEL } & \multicolumn{2}{|c|}{$\%$ OF NASALANCE IN VOWEL } \\
\hline & & $\begin{array}{c}\text { stressed V } \\
M \text { (SD) }\end{array}$ & $\begin{array}{l}\text { unstressed V } \\
M \text { (SD) }\end{array}$ & $\begin{array}{c}\text { stressed V } \\
M(\text { SD) }\end{array}$ & $\begin{array}{c}\text { unstressed V } \\
M \text { (SD) }\end{array}$ \\
\hline \multirow[t]{3}{*}{ AFP } & Slow & $74.03(36.42)$ & $70.93(36.74)$ & $43.39(16.70)$ & $44.19(17.28)$ \\
\hline & Normal & $76.93(37.37)$ & $71.45(38.26)$ & $44.70(17.22)$ & $46.80(18.22)$ \\
\hline & Fast & $78.48(37.12)$ & $78.55(37.57)$ & $49.18(20.72)$ & $54.67(20.79)$ \\
\hline \multirow[t]{3}{*}{ EMC } & Slow & $74.74(37.19)$ & $75.99(36.60)$ & $52.12(18.15)$ & $54.96(17.67)$ \\
\hline & Normal & $71.65(35.61)$ & $73.83(34.87)$ & $51.22(16.07)$ & $56.58(18.95)$ \\
\hline & Fast & $78.32(36.81)$ & $77.69(36.40)$ & $51.41(18.88)$ & $54.82(19.68)$ \\
\hline \multirow[t]{3}{*}{$X L G$} & Slow & $85.00(26.95)$ & $77.03(36.65)$ & $61.24(21.94)$ & $59.16(20.74)$ \\
\hline & Normal & $73.58(38.31)$ & $68.44(37.69)$ & $61.62(20.90)$ & $64.83(23.35)$ \\
\hline & Fast & $68.74(38.64)$ & $68.77(38.05)$ & $60.36(22.85)$ & $65.13(23.08)$ \\
\hline
\end{tabular}

The same tendencies outlined above can be seen in Table 3. Thus, speaker AFP's nasality and nasalance percent scores increase both in stressed and unstressed syllables, along with an increase in speaking rate. The opposite pattern is found in speaker XLG. In the case 
of speaker EMC, there are hardly any differences in nasalance values for stressed and unstressed syllables as a function of speaking rate, while lower nasality scores occur at a normal speaking rate. As in Table 2, the standard deviation values in Table 3 are higher for nasality than for nasalance both in stressed and unstressed vowels. Furthermore, Table 3 offers additional information as far as the stress position of the vowel is concerned. To be exact, it can be seen that nasality scores are for the most part higher in stressed vowels than unstressed vowels, as opposed to nasalance scores. Despite this, the ANOVAs computed only showed significant differences in the comparison between stressed and unstressed vowels at a normal speaking rate in speaker EMC's nasalance scores ( $p=.042)$. This is in line with previous findings, though studies like Krakow (1993: 143) and Beddor (2007: 249) have demonstrated large differences in the nasalization of stressed and unstressed vowels in a more reliable and consistent way.

Nonetheless, the present study aims to characterize nasalization in greater detail and to determine whether there are relevant differences regarding several phonic groups, that is, as a function of the vowel-nasal relationship with regard to syllable boundaries. For this purpose, the range in speaking rate and the variations in stress position are essential as these two parameters significantly influence gestural coproduction, which in turn helps to understand the phenomenon of coarticulation. As Krakow (1993: 31-32) states,

Identification of a segmental level of gestural organization and an understanding of the manner in which gestures for successive segments combine provide only a partial understanding of the nature of speech motor organization, however, because there are a number of other sources of influence. These include (but are not limited to) variations in syllable structure, syllable location in a phrase or sentence, stress, and speaking rate.

The difference in the various degrees of nasalization refers to duration, or the onset time of nasalization, rather than intensity. Figures 3 and 4 illustrate this difference at slow and fast speaking rates, respectively. From top to bottom, both figures include a nasal waveform, an oral waveform, a spectrogram, and a nasalance curve. In all graphic displays the nasalized area of the target vowel is selected and marked by blue vertical lines.

The blue vertical line on the right in Figures 3 and 4 shows that nasal airflow increases at the end of the nasalized vowel and the beginning of the following nasal, in other words, when the oral passage closes. As Regueira (2010) points out in his study of nasalization in Galician and Portuguese, this is an expected outcome because in the realization of the vowel the oral passage is open in a way that the energy is distributed into the energy exiting through the oral passage and the energy exiting through the nasal passage. By contrast, in the production of nasals the energy exiting through the nose might increase, as it is the only way out, the oral cavity being closed. Additionally, this fact results in lower values in the nasalance curve of vowels than that of nasals, even when vowels undergo a high degree of nasalization as Figures 3 and 4 illustrate. Similarly, the blue vertical line on the left of Figure 4 also demon- 


\section{FIGURE 3}

AFP's utterance Diga cantar todavía ('Say sing still') at a slow speaking rate. Cantar ('sing') belongs to Group 10 (/VN./)

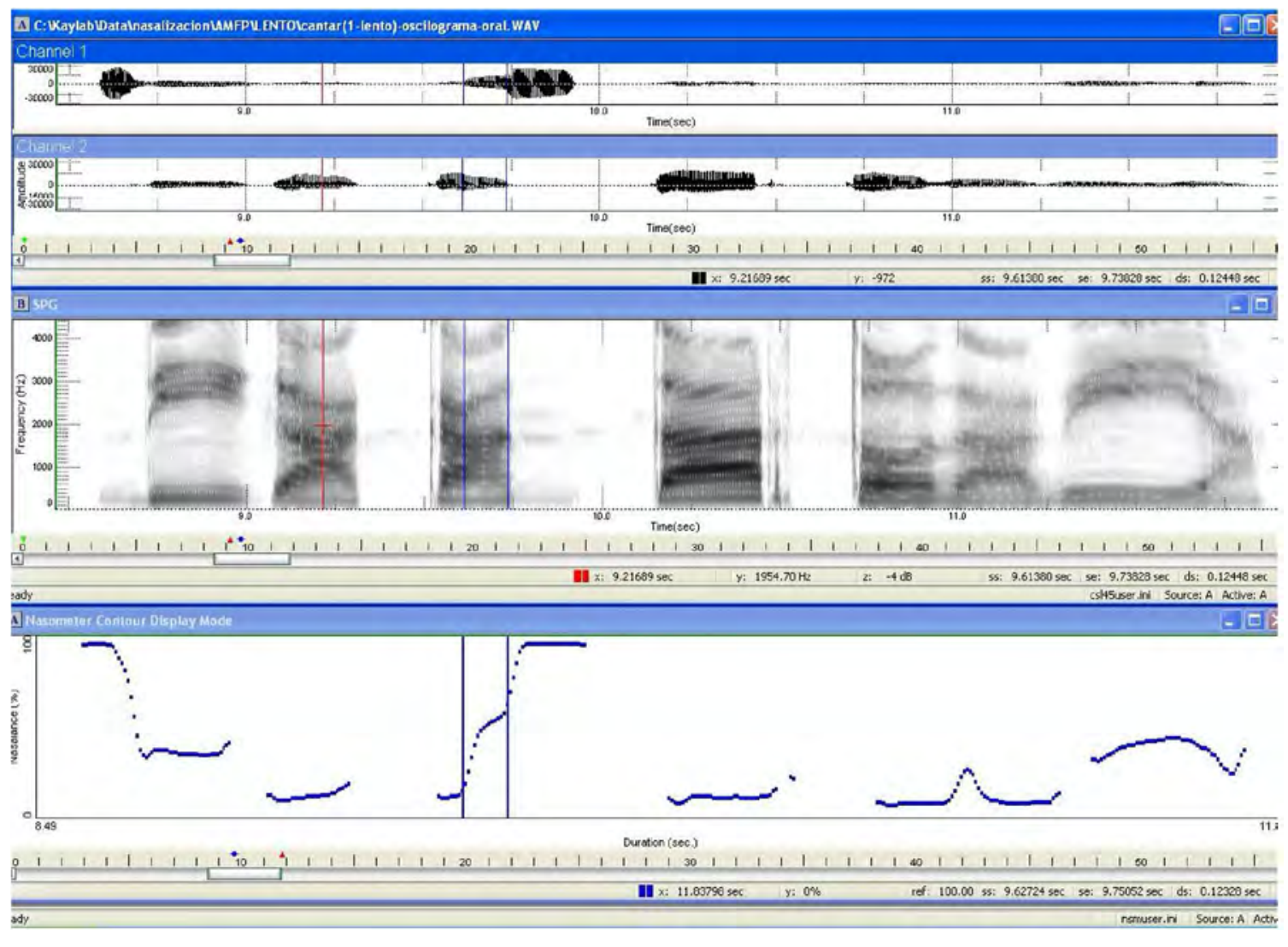

strates a decrease in the degree of nasality and nasalance when the oral passage opens at the beginning of the vowel following the end of the preceding nasal.

On the other hand, Figure 3 reveals that in the partially nasalized vowel when the air starts to exit through the nose there is a decrease in the intensity of the airflow exiting through the mouth. This is due to the fact that the energy must be distributed. This can be further seen in Figure 5 where nasality is highlighted by a red ellipsis. This change coincides with an increase in nasalance, which is visible on the bottom part of Figure 5.

Another aspect present in Figure 4 is worth mentioning. As noted before, in the word manta ('blanket') the vowel [a] in between the nasals [m] and [n] exhibits 100\% acoustic nasality from beginning to end of its realization. Additionally, in this utterance there is an instance of a vowel between an approximant consonant and a nasal belonging to the following stressed syllable-namely, Diga manta todavía ('Say blanket still'). Although [a] in Diga has a lower percentage of nasality than [a] in manta, the differences in intensity or in the degree of nasality 


\section{FIGURE 4}

AFP's utterance Diga manta todavía ('Say blanket still') at a fast speaking rate. Manta ('blanket') belongs to Group 5 (/NVN./)

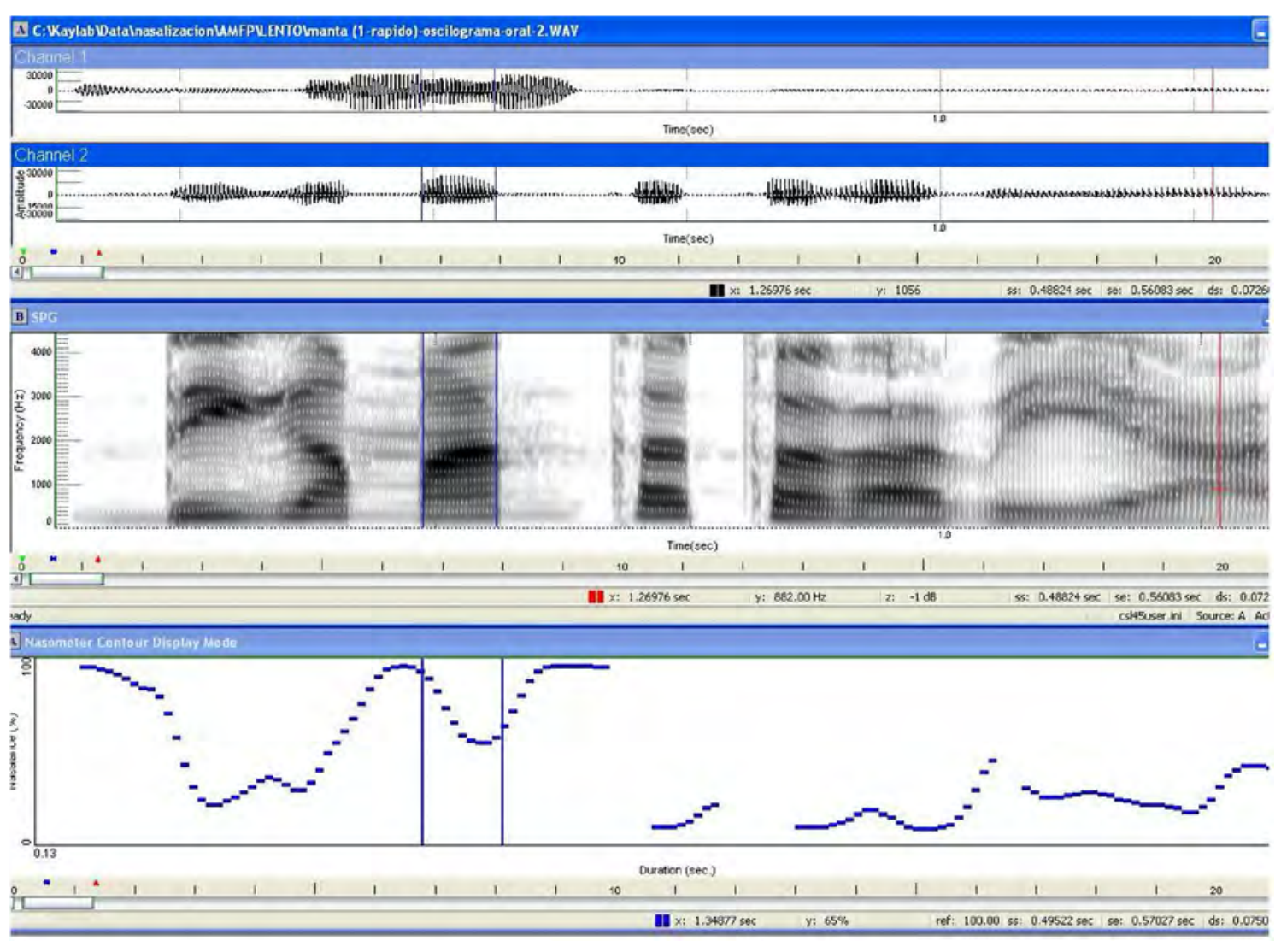

between the two sounds are barely discernible (see this result zoomed in and highlighted by a red oval in Figure 6). This finding is in agreement with previous investigations on Galician, e.g., Regueira (2010).

On the other hand, differences in the intensity of nasality can be found in some instances, for example, in speaker XLG's carrier sentence Diga camino todavía ('Say path still') produced at a normal speaking rate (see Figure 7).

In Figure 7 the three vowels in the word camino ('path') are selected and marked by vertical lines on both the nasal waveform (top) and the oral waveform (bottom), where the difference in nasality mentioned earlier can be easily seen. The Nasometer's nasalance values of the three vowels point to this difference: from left to right, $76 \%, 94 \%$, and $70 \%$. This dissimilarity might partly be due to the different timbre of vowels, as Regueira (2010), Clumeck (1976), and Rossato et al. (2003) have noted. In their work, the authors obtained higher scores for central vowels. In the present study, however, it is the high front vowel that exhibits higher scores, this vowel 


\section{FIGURE 5}

Word cantar ('sing') at a slow speaking rate produced by speaker AFP

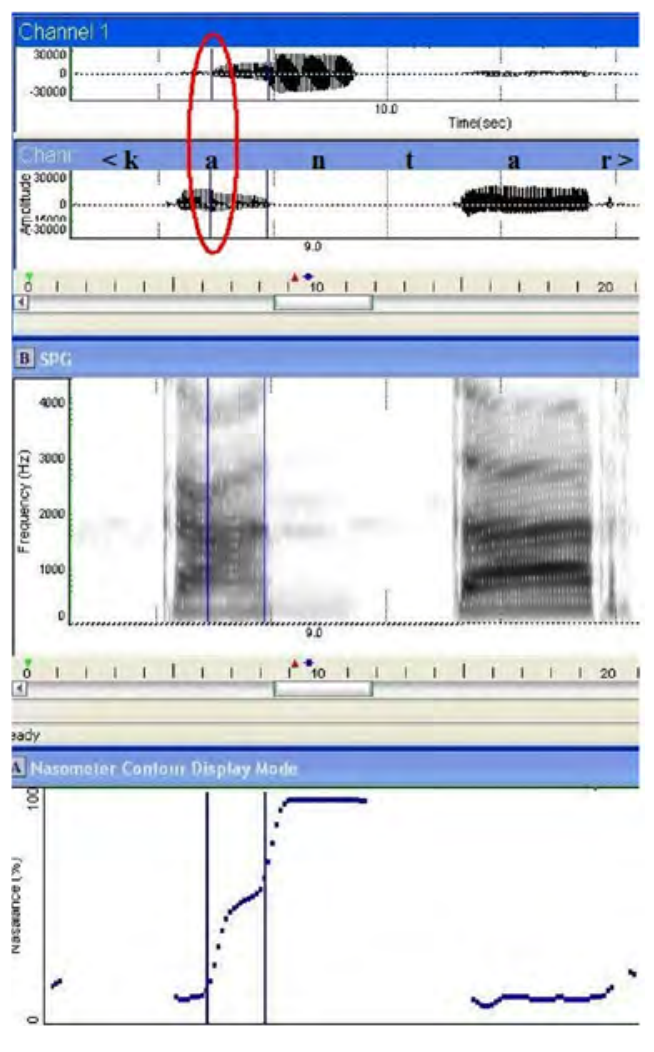

\section{FIGURE 6}

AFP's utterance (D)iga manta (todavía) ('Say blanket (still)') at a fast speaking rate

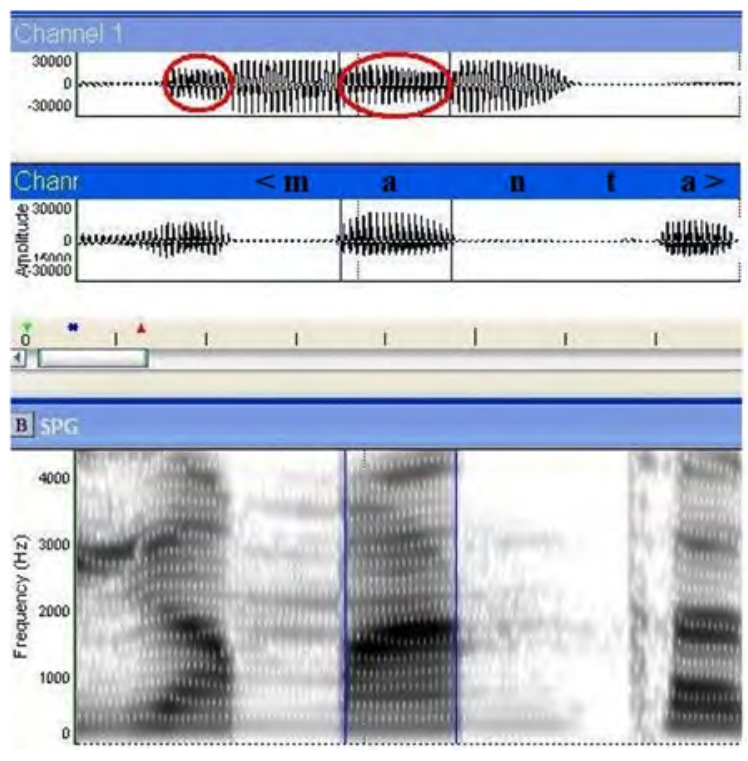




\section{FIGURE 7}

XLG's utterance Diga camino todavía ('Say path still') at a normal speaking rate. Camino ('path') belongs to Group 8 (/V.N/)

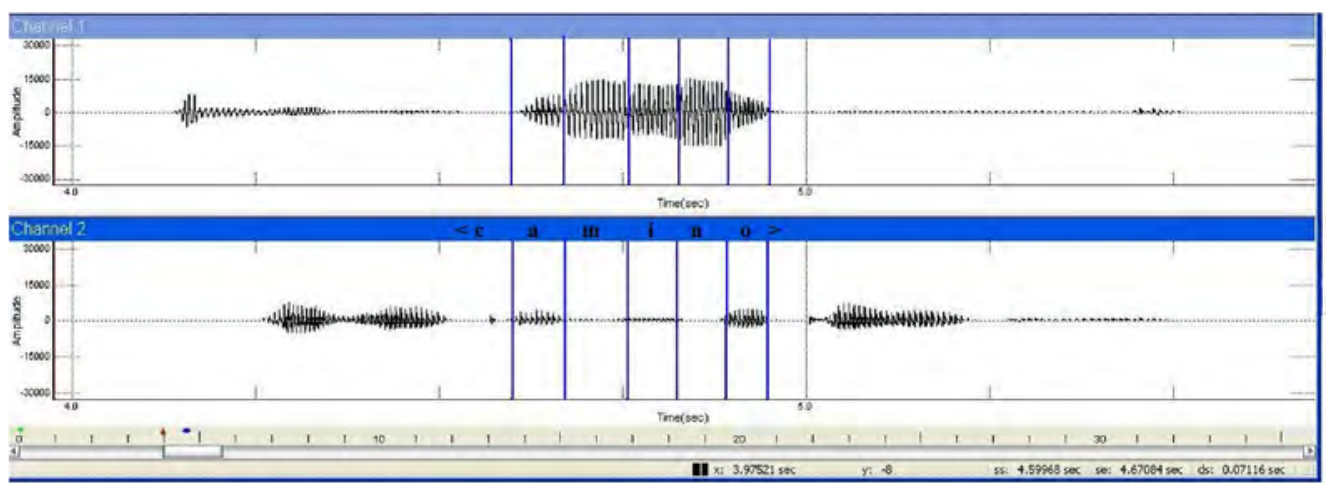

being produced in between nasals (i.e., /i/ in camino). Therefore, there is an obvious effect of the phonetic context in which the vowel appears on the vowel's percentage of nasalance.

Next, Table 4 includes the average values of each phonic group as a function of speaker, speaking rate, and stress position of the syllable within which the target vowel is uttered.

\section{TABLE 4}

Mean values of nasality and nasalance for each phonic group examined as a result of speaking rate (SR) and speaker

\begin{tabular}{|c|c|c|c|c|c|c|c|c|}
\hline \multirow[t]{2}{*}{$\begin{array}{l}\text { PHONIC } \\
\text { GROUP }\end{array}$} & \multirow[t]{2}{*}{$\begin{array}{l}\text { SYLLABLE } \\
\text { STRESS }\end{array}$} & \multirow[t]{2}{*}{ SR } & \multicolumn{3}{|c|}{$\begin{array}{l}\text { MEAN PERCENTAGE } \\
\text { OF NASALITY IN V }\end{array}$} & \multicolumn{3}{|c|}{$\begin{array}{l}\text { MEAN PERCENTAGE } \\
\text { OF NASALANCE IN V }\end{array}$} \\
\hline & & & AFP & EMC & XLG & AFP & EMC & XLG \\
\hline \multirow[t]{6}{*}{ Control } & \multirow{3}{*}{$\begin{array}{l}\text { Stressed } \\
\text { (group 1) }\end{array}$} & slow & -- & -- & 40.35 & 10.93 & 13.80 & 13.20 \\
\hline & & normal & -- & -- & -- & 11.07 & 18.60 & 18.33 \\
\hline & & fast & -- & -- & -- & 11.13 & 14.40 & 14.20 \\
\hline & \multirow{3}{*}{$\begin{array}{l}\text { Unstressed } \\
\text { (group 7) }\end{array}$} & slow & -- & -- & -- & 9.53 & 18.20 & 13.80 \\
\hline & & normal & -- & -- & -- & 11.53 & 17.93 & 15.27 \\
\hline & & fast & -- & -- & -- & 14.07 & 14.53 & 17.33 \\
\hline \multirow[t]{6}{*}{ /V.N/ } & \multirow{3}{*}{$\begin{array}{l}\text { Stressed } \\
\text { (group 2) }\end{array}$} & slow & 69.56 & 67.43 & 77.51 & 37.47 & 53.60 & 69.53 \\
\hline & & normal & 64.28 & 62.47 & 56.60 & 42.60 & 58.87 & 64.80 \\
\hline & & fast & 79.68 & 74.25 & 43.72 & 46.40 & 49.73 & 67.93 \\
\hline & \multirow{3}{*}{$\begin{array}{l}\text { Unstressed } \\
\text { (group 8) }\end{array}$} & slow & 54.00 & 71.93 & 72.04 & 42.00 & 61.07 & 69.53 \\
\hline & & normal & 53.26 & 78.89 & 54.75 & 42.00 & 57.07 & 72.67 \\
\hline & & fast & 82.75 & 85.42 & 49.91 & 56.27 & 59.73 & 76.40 \\
\hline
\end{tabular}




\begin{tabular}{|c|c|c|c|c|c|c|c|c|}
\hline \multirow[t]{6}{*}{ /NV./ } & \multirow{3}{*}{$\begin{array}{l}\text { Stressed } \\
\text { (group 3) }\end{array}$} & slow & 100 & 100 & 100 & 49.60 & 54.87 & 67.73 \\
\hline & & normal & 100 & 85.15 & 97.34 & 48.93 & 52.67 & 62.87 \\
\hline & & fast & 98.14 & 97.05 & 98.69 & 44.47 & 51.33 & 54.93 \\
\hline & \multirow{3}{*}{$\begin{array}{l}\text { Unstressed } \\
\text { (group 9) }\end{array}$} & slow & 98.12 & 100 & 100 & 51.47 & 54.40 & 65.60 \\
\hline & & normal & 100 & 86.35 & 100 & 52.20 & 60.53 & 69.60 \\
\hline & & fast & 100 & 95.83 & 100 & 55.40 & 55.40 & 61.00 \\
\hline \multirow[t]{6}{*}{ NN./ } & \multirow{3}{*}{$\begin{array}{l}\text { Stressed } \\
\text { (group 4) }\end{array}$} & slow & 74.64 & 99.03 & 92.11 & 47.00 & 59.67 & 72.13 \\
\hline & & normal & 96.94 & 82.31 & 87.54 & 46.93 & 54.33 & 68.47 \\
\hline & & fast & 93.07 & 98.62 & 70.05 & 53.60 & 55.80 & 70.60 \\
\hline & \multirow{3}{*}{$\begin{array}{l}\text { Unstressed } \\
\text { (group 10) }\end{array}$} & slow & 73.48 & 84.03 & 90.11 & 45.20 & 59.67 & 69.60 \\
\hline & & normal & 75.42 & 77.72 & 55.87 & 48.20 & 61.73 & 68.87 \\
\hline & & fast & 88.54 & 84.89 & 62.69 & 54.93 & 61.33 & 77.47 \\
\hline \multirow[t]{6}{*}{ /NVN./ } & \multirow{3}{*}{$\begin{array}{l}\text { Stressed } \\
\text { (group 5) }\end{array}$} & slow & 100 & 100 & 100 & 56.53 & 66.73 & 74.33 \\
\hline & & normal & 100 & 100 & 100 & 58.27 & 61.73 & 80.40 \\
\hline & & fast & 100 & 100 & 100 & 69.53 & 67.93 & 80.00 \\
\hline & \multirow{3}{*}{$\begin{array}{l}\text { Unstressed } \\
\text { (group 11) }\end{array}$} & slow & 100 & 100 & 100 & 60.00 & 69.00 & 70.87 \\
\hline & & normal & 100 & 100 & 100 & 62.73 & 72.40 & 82.40 \\
\hline & & fast & 100 & 100 & 100 & 73.47 & 70.73 & 80.20 \\
\hline \multirow[t]{6}{*}{ /NV.N/ } & \multirow{3}{*}{$\begin{array}{l}\text { Stressed } \\
\text { (group 6) }\end{array}$} & slow & 100 & 100 & 100 & 58.80 & 64.07 & 70.53 \\
\hline & & normal & 100 & 100 & 100 & 60.40 & 61.13 & 74.87 \\
\hline & & fast & 100 & 100 & 100 & 69.93 & 69.27 & 74.47 \\
\hline & \multirow{3}{*}{$\begin{array}{l}\text { Unstressed } \\
\text { (group 12) }\end{array}$} & slow & 100 & 100 & 100 & 56.93 & 67.40 & 65.53 \\
\hline & & normal & 100 & 100 & 100 & 64.13 & 69.80 & 82.20 \\
\hline & & fast & 100 & 100 & 100 & 73.87 & 67.20 & 78.40 \\
\hline
\end{tabular}

Alternatively, the same values of Table 4 can be displayed in graphic format (see Figure 8). In what follows, a number of comments about this data are made.

In general terms, the percent scores of nasality are higher than those of nasalance for the three speakers and speaking rates. The exception to this is to be found in speaker XLG's production of groups 2, 8, and 10-i.e., in those sequences where the vowel is followed by a nasal that either belongs to the same syllable or to the following syllable: stressed /V.N/, unstressed N.N/, and unstressed /VN./ sequences, respectively_at normal and fast speaking rates.

It is noteworthy that even in vowels adjacent to non-nasal consonants, where usually there is no trace of acoustic nasality, a small amount of airflow exiting through the nose was ob- 


\section{FIGURE 8}

Mean values of nasality and nasalance for each phonic group analyzed as a function of speaking rate and speaker

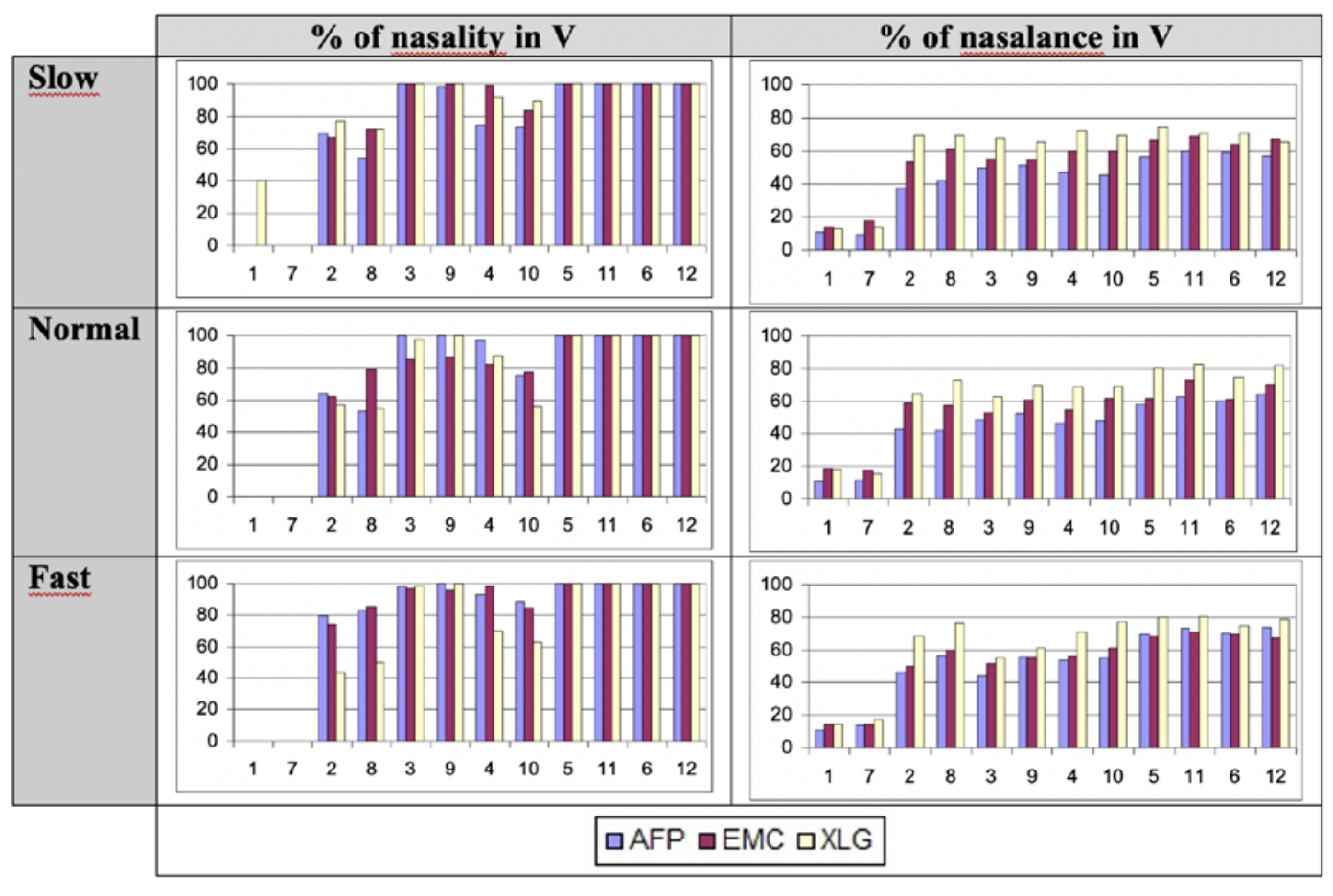

served. In turn, this resulted in a small percentage of nasalance in all the speakers' utterances. As to control sequences, irrespective of whether the vowel appears in a stressed syllable (group 1) or in an unstressed syllable (group 7), the percentage of nasality and nasalance in the vowel differed significantly from vowels in other phonic groups at all speaking rates $(p=$ .000). However, the comparison of nasality and nasalance values of vowels from group I with group 7 was nonsignificant, except for speaker XLG's sequences produced at a slow speaking rate. The latter finding constitutes an individual trait in that several of the speaker's stressed vowels at a slow speaking rate exhibited a notable percentage of nasality (see Table 4 and Figure 8 above). By way of example, Figure 9 shows this significant degree of nasality in the two vowels of the word paso ('step') from the utterance Diga paso todavía ('Say step still') on the nasal waveform (top). Specifically, as marked by the vertical lines on the waveform, nasality spreads over approximately half the duration of the first vowel of the word and throughout the duration of the second vowel.

Clumeck (1976) stated that, along with a tendency of the velum to be more open during the production of low vowels than high vowels, the velopharyngeal port is not always closed during the production of oral vowels. Thus, speaker XLG's productions such as those of Figure 9 might be considered as an instance of excessive relaxation of the velum, which would 


\section{FIGURE 9}

XLG's utterance Diga paso todavía ('Say step still') at a slow speaking rate. Paso

('step') belongs to Group 1 (control)

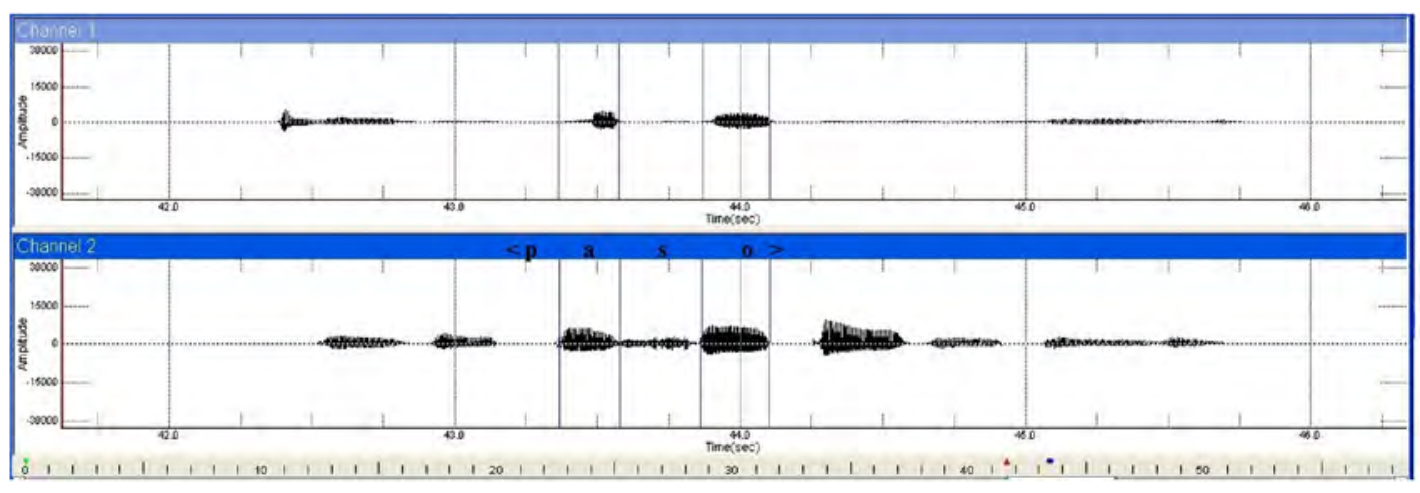

not be expected in this context. Therefore, a slow speaking rate certainly contributes to this hyperarticulation effect. In any case, no further exemplars of this sort were observed for the remaining speaking rates and speakers.

Additional analyses of variance on nasality and nasalance scores with speaker and speaking rate as factors yielded significant differences $(p=.000)$. Next, the statistical results obtained are reported separately for each dependent variable.

As to the percentage of nasality in the vowel, the stressed vowel tended to have slightly higher values than the unstressed vowel at all speaking rates in all speakers and phonic groups, with the exception of speaker EMC in the phonic groups 2-8 (stressed-unstressed /V.N/ sequences). According to Scheffé post-hoc tests, the tendency of higher nasality scores in the stressed vowel was significant in those instances where the vowel was followed by a nasal whether in the same syllable or not. Specifically, significant results were found for speaker AFP in groups 2-8 at a slow speaking rate $(p=.001)$ and groups 4-10 at a normal speaking rate $(p=.000)$; speaker EMC in groups 2-8 at a normal speaking rate $(p=.000)$ and in groups $4-10$ at slow and fast speaking rates ( $p=.000$ and $p=.008$, respectively); and speaker XLG in groups 4-10 at a normal speaking rate $(p=.000)$.

When the vowel in question appears between two nasals-i.e., stressed-unstressed /NVN./ sequences (groups 5-11) and stressed-unstressed /NV.N/ sequences (groups 6-12)_it always has 100\% nasality throughout its duration at all speaking rates and in all speakers. Consequently, the comparisons between these groups were nonsignificant.

Regardless of whether the target vowel is uttered in a stressed or unstressed syllable, the stressed-unstressed /NV./, /NVN./, and /NV.N/ sequences (groups 3-9, 5-11, and 6-12, respectively) contribute to obtaining 100\% nasality scores at various speaking rates. This is consistently observed in the three speakers' stressed vowels at a slow speaking rate, in addition to speaker 
XLG's unstressed vowels at any speaking rate. In other words, the percentage of nasality in the vowel increases when the vowel is between nasals. This happens both when the nasal closes the syllable and when it belongs to the following syllable, though in the latter case the percentage of nasality is lower.

In the case of a given vowel being adjacent to one nasal only, the vowel has a higher percentage of nasality if the nasal precedes the vowel, namely, in /NV./ sequences (groups 3-9). On the other hand, if the vowel is followed by a nasal, for all speakers and at all speaking rates the vowel will have a higher nasality rate if the nasal closes the syllable within which the vowel appears-i.e., /VN./ sequences (groups 4-10) - as opposed to a lower percentage of nasality in the vowel if the nasal following the vowel belongs to a heterosyllabic sequence bearing the stress-i.e., /V.N/ sequences (groups 2-8). The following pairwise comparisons were significant $(p<.05)$ for speaker AFP: groups 2 vs. 3, 3 vs. 4, 8 vs. 9,8 vs. 10, and 9 vs. 10 at a slow speaking rate; groups 2 vs. 3, 2 vs. 4, 8 vs.9, 8 vs. 10, 9 vs. 10 at a normal speaking rate; and groups 2 vs. 3 and 8 vs. 9 at a fast speaking rate. In the case of speaker EMC, significant differences were located between groups 2 and 3, 2 and 4, 8 and 9, 8 and 10, and 9 and 10 at a slow speaking rate; and between groups 2 and 3 and groups 2 and 4 at normal and fast speaking rates. Finally, the differences in nasality scores for speaker XLG were significant in groups 2 vs. 3 and 8 vs. 9 at a slow speaking rate; groups 2 vs. 3, 2 vs.4, 8 vs. 9, and 9 vs. 10 at a normal speaking rate; and groups 2 vs. 3, 2 vs. 4, 3 vs. 4, 8 vs. 9, and 9 vs. 10 at a fast speaking rate. The fact that there were many significant comparisons indicates, on the one hand, that context plays an important role in determining the percentage of nasality in the vowel. On the other hand, the decrease in the number of significant comparisons along with an increase in speaking rate for two speakers (AFP and EMC) - and an increase in the number of significant comparisons for speaker XLG_emphasizes the importance of speaking rate with respect to vowel nasalization. Thus, as outlined above, speaker AFP's nasality scores are higher as speaking rate increases, as opposed to speaker XLG; while speaker EMC obtains lower nasality scores at a normal speaking rate and progressively higher scores first at a slow speaking rate and then at a fast speaking rate.

Regarding speaking rate and each phonic group, the ANOVAs conducted on the nasality scores showed that there were significant differences $(p<.005)$. Scheffé post-hoc tests revealed that for speaker AFP those significant differences occurred in groups 2 (stressed $/$ V.N/ sequences), 4 (stressed /VN./ sequences), and 8 (unstressed /V.N/ sequences) between slow and fast speaking rates, and in group 8 between normal and fast speaking rates. Variations in speaking rate turned out to be significant as well for speaker EMC in groups 4, 8, 9 (unstressed /VN./ sequences), and 11 (unstressed /NVN./ sequences) between slow and normal speaking rates, in group 8 between slow and fast speaking rates, and in groups 2, 4, 8, and 9 between normal and fast speaking rates. Likewise, significant differences in speaker XLG's nasality scores as a result of speaking rate were observed, specifically, in groups 1, 2, 8, and 10 between slow and normal speaking rates, in groups 1, 2, 4, 8, and 10 between slow and fast speaking rates, and in 
group 4 between normal and fast speaking rates. The large number of significant differences found might be taken as evidence of the active interplay between vowel nasalization, phonetic context, and speaking rate. That is, a vowel adjacent to only one nasal will most likely be influenced by speaking rate to a greater extent than a vowel between two nasals, hence affecting the percentage of nasality in that vowel.

Based on all of the results reported above, a hierarchy for the percentage of nasality in vowels could be suggested for Spanish. As Figure 10 shows, the nasality rate progressively increases from the control sequences (containing no vowel next to a nasal), through /V.N/, /VN./, and /NV./ sequences, to /NVN./ and /NV.N/ sequences. It should also be noted that in Figure 10 the box including the control sequences (groups 1 and 7) is smaller in size than the other boxes to indicate the striking difference in nasality scores for the control words when compared to the contextual conditions of nasalization in the study.

FIGURE 10

Generalization of the progression in the percentage of nasality in the vowel

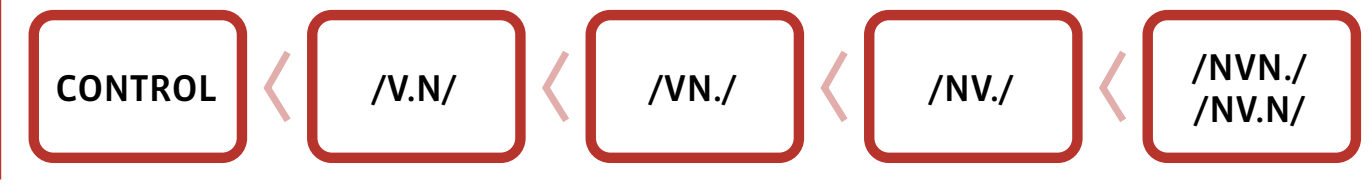

As far as the percentage of nasalance in the target vowel is concerned, significant differences were found between the control groups ( 1 and 7 ) and the other phonic groups ( $p<.001$ ). But the comparison between the two control groups was nonsignificant, as all nasalance scores obtained were considerably lower at all speaking rates and in all speakers.

A closer look at nasalance scores shows that all speakers for the most part tended to obtain higher scores for unstressed vowels than stressed vowels in any syllabic relationship between vowel and adjacent nasal(s). This trend is less evident, though, at a slow speaking rate, which normally creates a favourable scenario for hyperarticulation. Significant differences in scores were found for speaker AFP between groups 2 and $8(p=.047)$ and groups 3 and $9(p=.012)$ at a fast speaking rate. Differences were also significant for speaker EMC between groups 2 and $8(p=.002)$, 5 and $11(p=.008)$, and 2 and 8 ( $p=.012)$ at slow, normal, and fast speaking rates, respectively. Variations in nasalance scores for speaker XLG were not statistically significant.

Relating to phonetic context, a vowel adjacent to only one nasal exhibits a higher amount of nasalance if the nasal is within the same syllable as the vowel (be it located before or after the vowel) for speaker AFP. In the case of the two male speakers, the percentage of nasalance gradually increases in the following order: /NV./ (groups 3-9) < N.N/ (groups 2-8) < NN./ (groups 4-10). Scheffé post-hoc tests revealed a large number of significant differences between vowels in stressed position and vowels in unstressed position (or between the same contexts 
differing in stress position) $(p<.05)$. For speaker AFP those differences were located between groups 2 and 3, 2 and 4, and 8 and 9 at a slow speaking rate; and between groups 2 and 8, and 3 and 9 at a fast speaking rate. For speaker EMC the differences occurred between groups 2 and 4, 2 and 8 , and 8 and 9 at a slow speaking rate; and between groups 2 and 8 at a fast speaking rate. And for speaker XLG the comparisons between groups 2 and 3, 3 and 4, 8 and 9, and 9 and 10 at a fast speaking rate were significant.

When a vowel appears between two nasals - both within the same syllable (groups 5 and 11) and in separate syllables (groups 6 and 12)-variations in the percentage of nasalance between vowels in the contexts just specified were small. Accordingly, the pairwise comparisons between groups 5 and 6,11 and 12,5 and 11 , and 6 and 12 were nonsignificant for any of the speakers, except for the comparison between groups 5 and 11 at a normal speaking rate for speaker $\operatorname{EMC}(p=.008)$.

By contrast, the comparison of the groups containing a vowel between two nasals (in tautosyllabic sequences-/NVN./ sequences or groups 5-11_or in heterosyllabic sequences/NV.N/ sequences or groups 6-12) with the groups having a vowel adjacent to one nasal only (N.N/, /NV./, and /VN./ sequences or groups 2-8, 3-9, and 4-10, respectively) yielded significant differences in nasalance scores for speaker AFP in all possible context comparisons and at all speaking rates, in nearly all possible context comparisons for speaker EMC (except for groups 4-6 at a slow speaking rate; groups 2-5, 2-6, 3-5, 3-6, 4-5, 4-6, 9-12, and 10-12 at a normal speaking rate; and groups 8-12 and 10-12 at a fast speaking rate), and in almost all possible comparisons for speaker XLG (groups 3-5 at a slow speaking rate; groups 2-5, 2-6, 3-5, 3-6, 4-5, 8-11, 9-11, 9-12, 10-11, and 10-12 at a normal speaking rate; and groups 2-5, 3-5, 3-6, 9-11, and 9-12 at a fast speaking rate).

As was the case of nasality, an increase in speaking rate usually entailed a higher percentage of nasalance. This could be noted particularly for speaker AFP. Although there was not always a constant progression from slower to faster speaking rates, her nasalance scores were often higher at a fast speaking rate. On the other hand, nasalance scores were higher at a normal speaking rate-and occasionally at a slow speaking rate-for speakers EMC and XLG. Furthermore, significant differences in nasalance scores as a function of speaking rate were observed for the following phonic groups $(p<.05)$. First, for speaker AFP, significant differences in nasalance scores were found in groups 2 (slow vs. fast speaking rates), groups 4, 5, 6, 8, 10, and 11 (all slow vs. fast speaking rates and normal vs. fast speaking rates), and group 12 (slow vs. fast speaking rates, slow vs. normal speaking rates, and normal vs. fast speaking rates). Speaker EMC had significant differences in groups I (slow vs. normal speaking rates and slow vs. fast speaking rates), 2 (slow vs. normal speaking rates and normal vs. fast speaking rates), 4 (slow vs. normal speaking rates), 5 (slow vs. normal speaking rates and normal vs. fast speaking rates), 6 (slow vs. normal speaking rates, slow vs. fast speaking rates, and normal vs. fast speaking rates), 7 (slow vs. fast speaking rates), 9 (slow vs. normal speaking rates), and 1 (slow 
vs. normal speaking rates). Last, the following differences in nasalance scores were significant for speaker XLG: groups I (slow vs. normal speaking rates and normal vs. fast speaking rates), 3 (slow vs. fast speaking rates and normal vs. fast speaking rates), 5 (slow vs. normal speaking rates and slow vs. fast speaking rates), 6 (slow vs. normal speaking rates and slow vs. fast speaking rates), 7 (slow vs. fast speaking rates and normal vs. fast speaking rates), 8 (slow vs. fast speaking rates), 9 (normal vs. fast speaking rates), 10 (slow vs. fast speaking rates and normal vs. fast speaking rates), 11 (slow vs. normal speaking rates and slow vs. fast speaking rates), and 12 (slow vs. normal speaking rates and slow vs. fast speaking rates).

Finally, and as previously suggested for nasality (see Figure 10 above), a hierarchy for the percentage of nasalance might also be proposed for Spanish vowels. Figure 11 below illustrates this proposal.

\section{FIGURE 11}

Generalization of the progression in the percentage of nasalance in the vowel

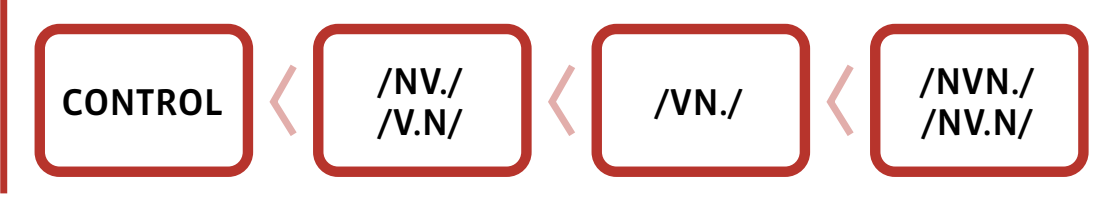

\section{Discussion}

As stated at the beginning of this paper, in his Manual de pronunciación española (1918), Navarro Tomás addresses nasalization (1985 [1918]: 35) by pointing out that

A veces la consonante nasal final de sílaba influye sobre la vocal precedente, nasalizándola en más o menos parte [...]. Una vocal entre dos consonantes nasales resulta, en general, completamente nasalizada [...].

Sometimes the consonant in syllable-final position influences the preceding vowel, by nasalizing it to a greater or lesser extent [...]. A vowel between two nasal consonants frequently undergoes full nasalization [...]. [author's own translation]

The author seems to consider that the greatest degree of nasalization occurs in a vowel between two nasals (completamente nasalizada ["undergoes full nasalization"]), although he does not specify whether the nasal following the vowel should be in syllable coda position or not. The author also acknowledges the fact that there can be several degrees of nasalization (a veces ["sometimes"]) in a vowel followed by a nasal in syllable coda position. That is, the author makes reference to anticipatory or regressive coarticulation-or right-to-left coarticulation. However, the author does not address the sequence composed of a vowel preceded by a nasal (within the same syllable), in which if there were any trace of nasalization, it would be a carryover, perseverative or progressive-or left-to-right_coarticulatory effect. Therefore, 
given that a nasal closing a syllable results in different degrees of anticipatory nasalization and that a vowel between two nasals is fully nasalized, it seems plausible to think that a nasal preceding a vowel can also have an effect. That is, there must be some type of carryover coarticulation, although Navarro Tomás did not comment on this matter.

Groups 3-9, 4-10, and 2-8 from the corpus of this study (/NV./, /VN./, and /V.N/ sequences, respectively) can be considered in order to determine the effects of anticipatory vs. carryover coarticulation of nasals on adjacent vowels in Spanish. On the whole, the percentage of nasality is higher in a vowel preceded by a nasal (carryover coarticulation effect) than in a vowel followed by a nasal (anticipatory coarticulation effect). This is different from the percentage of nasalance, though variations in this parameter are not so prominent. According to the percentage of nasality and nasalance, the effect of the nasal on both variables is larger if the nasal is within the same syllable as the vowel than if the nasal belongs to the following stressed syllable. Thus, carryover coarticulation appears to be more relevant than anticipatory coarticulation, which supports previous investigations reporting on a greater influence of perseverative coarticulation than anticipatory coarticulation (e.g., Delvaux et al., 2008). As for anticipatory coarticulation, the condition that favours this type of coarticulation entails the presence of the nasal within the same syllable as the vowel undergoing nasalization. Moreover, the findings from this study on anticipatory coarticulation for Spanish coincide with those of Regueira (2010) for Galician, who observed a higher percentage of nasalization in the vowel when the following nasal was in syllable coda position.

It should be further noted that anticipatory coarticulation is often the main focus of articulation studies, as it involves, with regard to coproduction, the speaker's preplanning to the organization of the motor system for the articulation of speech segments (Chafcouloff \& Marchal, 1999: 74-75; Reetz \& Jongman, 2008: 39). On the other hand, progressive coarticulation "is often regarded as arising primarily from 'inertia' in the speech production mechanism" (Flege, 1988: 525). Despite this, Daniloff and Hammarberg (1973) indicate that perseverative coarticulation is deliberate since there is evidence that its effects are more noticeable at a slow speaking rate (Bell-Berti, 1993: 71). However, the latter statement was only partly confirmed in the present study. To be exact, the data analysis of groups 3-9, which constitute examples of carryover coarticulation, showed that this was the case of stressed vowels, whereas for unstressed vowels higher nasality and nasalance scores occurred at a fast speaking rate.

In the phenomenon of coarticulation there is certain tension concerning gestural coproduction between gestures comprising segments with stricter articulation due to more precise requirements and gestures whose articulation need not be so strict. In other words, there are, on the one hand, more enduring and influential gestures in other gestures and, on the other hand, somewhat weaker or more permeable gestures to neighbouring gestures. Focusing on nasalization, lowering the velopharyngeal mechanism is a necessary condition in the pro- 
duction of nasal consonants, as this gesture characterizes nasal sounds as opposed to oral segments. This makes the gesture to be a very strict requirement and, therefore, a very strong gesture that can superimpose itself onto other gestures, in particular, weaker gestures as compared to this articulator. In this regard, vowels in Spanish belong to this group of weaker gestures, as vowels are oral sounds and, in principle, the velum does not play an important role in vowel production. As a result, the velum can adopt the gesture of the adjacent nasal without losing the vowel timbre, whether the nasal precedes or follows the vowel and, especially, if the vowel is between two nasals-hence the variability in velum height among oral and nasal vowels observed in Rossato, Badin, and Bouaouni (2003). The importance of carryover coarticulation over anticipatory coarticulation-even if the former is a by-product of the inertia of gestures - in the nasalization of adjacent vowels is due to the fact that the velum does not have a decisive function and does not interfere in vowel production, and so the velum can be superimposed onto vowel production.

As speaking rate increases, the larger the overlap among the articulatory gestures of neighbouring or adjacent segments is. Bell-Berti and Krakow (1991) looked at this superposition of velum lowering in normal vs. fast speech. In the present study, the speakers exhibited three different strategies concerning the percentage of nasality and nasalance in vowels as a result of variations in speaking rate. Strange though it may seem at first, this finding is, in fact, quite common in the literature. For instance, work on French oral and nasal vowels by Engwall, Delvaux, and Metens (2006) revealed large differences among the four participants of the study. The results also suggested that the speakers' anatomy of their oral and nasal tracts influence articulation to such a degree that inter-speaker differences in the configuration of the vocal tract and velum opening are accounted for as a response to the need to establish an appropriate relationship between the oral and the nasal resonators. Figure 12 below (adapted from Engwall et al., 2006) illustrates through magnetic resonance imaging (MRI) the above-mentioned differences in the configuration of the vocal tract and velum opening between two female speakers' production of an oral vowel and a nasal vowel.

\section{FIGURE 12}

MRIs of two different speakers' French oral and nasal vowels (adapted from Engwall, Delvaux \& Metens, 2006: 4). Note the velum and tongue position, in addition to the resulting oral and nasal cavity areas, in the production of the two types of vowels

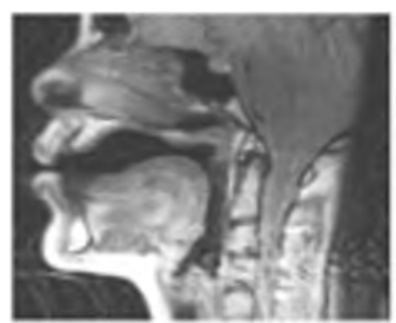

(a) $\mathrm{Fl} . / \mathrm{o} /$

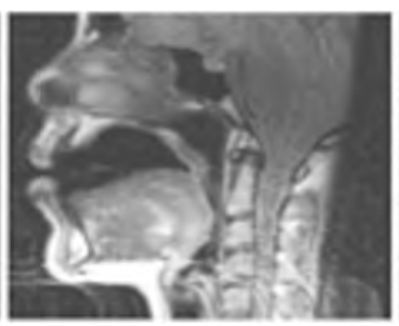

(b) $\mathrm{F} 1, / \mathrm{s} /$

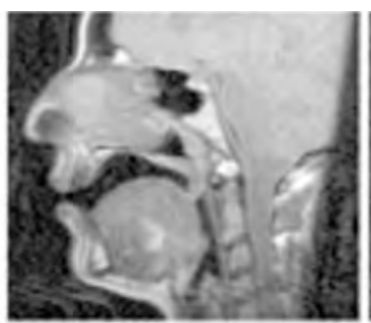

(c) $\mathrm{F} 2, / \mathrm{o} /$

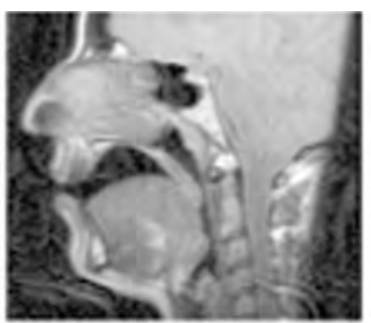

(d) $\mathrm{F} 2, / 3 /$ 
As the results of the present study demonstrated, when the nasal is in syllable coda position, anticipatory coarticulation entails a percentage of nasality of at least three quarters (75\%) of the vowel duration. And if the nasal after the target vowel is in the following stressed syllable, nasality values are approximately between half and three quarters of the vowel duration. The result on the percentage of nasality when the nasal is in syllable coda position is similar to Regueira (2010: 88), who found that vowels preceding a nasal in syllable coda position in Galician had a percentage of nasality of about 70\%. On the other hand, Montagu (2007) observed that the percentage of nasality in French vowels with a nasal closing the syllable was nearly always below 50\%, nasality being evident in the second part of the vowel duration. According to the author, this finding derives from the need to maintain the distinction between partially nasalized vowels through context and nasal vowels in French, which in turn leads speakers to limit nasal coarticulation during vowel production. Therefore, anticipatory nasalization in French is more constrained than carryover nasalization. Conversely, the lack of nasal vowels in Spanish and Galician favours the fact that contextual nasalization displays higher nasality values than those of languages containing phonological nasal vowels.

Coarticulation can be viewed as the result of the temporal overlap (or coproduction) between speech movements that are typical of consecutive segments (Bell-Berti \& Harris, 1981; Fowler, 1980; Munhall \& Löfqvist, 1992; Saltzman \& Munhall, 1989). This view has found support in the examination of the articulators of the oral tract-i.e., lips, lower jaw, and tongue-carried out in studies such as Bell-Berti and Harris (1981), Fowler (1980), Saltzman and Munhall (1989), and even an early paper by Ohman (1966). Several other studies on the velum also corroborate this notion, e.g., Bell-Berti and Krakow (1991) and Krakow (1993). As to anticipatory coarticulation, Farnetani (1999) points out that there are not only variations among languages, but also within the same language, as is the case of American English as reported in Moll and Daniloff (1971), Bell-Berti and Harris (1981), and Solé and Ohala (1991). Farnetani (1999) further hypothesizes that these differences might arise from the use of different experimental techniques and speech material (e.g., different speaking styles or rates) and that these divergences might indicate dialectal variants or suggest emergent sound changes.

In most of the world's languages that contain nasal vowels from the phonological point of view, such as French and Portuguese, it is held that they originated diachronically by means of full nasalization of a vowel followed by a nasal and the subsequent dropping of syllable-final nasals (Ruhlen, 1975). That is, vowel nasalization is seen as the result of a process that initially encompasses regressive assimilation. In languages without phonological nasal vowels, Clumeck (1976) and Solé (1995) state that there can be two types of actions. On the one hand, there might be partial nasalization of oral vowels. On the other hand, nasalization might be more extended as if the articulatory target were to produce a nasal vowel resulting from a phonological rule. As noted above, the results of the present study showed differences in the percentages of vowel nasality and vowel nasalance as a function of the several parameters examined, attaining 100\% nasality and nasalance scores for vowels between two nasals. 


\section{Conclusions}

This study was aimed at examining the characteristics of contextual phonetic nasalization in Spanish by means of a Nasometer. Based on the results obtained, the Nasometer proved to be a very useful tool to investigate nasalization as well as very specific details relevant to experimental phonetics. To be precise, through the Nasometer differences in nasalized vowels -in terms of percentage of nasality and percentage of nasalance-for each speaker could be observed as a function of speaking rate, stress position, and the syllabic relationship between the nasal (or nasals) and the vowel under investigation.

Although the three speakers' production had to be analyzed separately due to the significant differences in the nasality and nasalance scores observed among them, on the whole the findings from the present study indicated that contextual vowel nasalization in Spanish is favoured when the target vowel is uttered between two nasals. In this case, nasality and nasalance scores were higher than in other sequences/phonic groups. The results also showed that there was even a higher degree of nasalization, in particular the percentage of nasality, when there was only one adjacent nasal to the vowel. In turn, the amount of nasalization was greater if the adjacent nasal preceded the vowel within the same syllable than if the nasal followed the vowel. In the latter case, the influence of the nasal was larger if it closed the syllable than if it belonged to the following syllable. Additionally, the results demonstrated that the percentage of nasalance obtained on the /NV./, /VN./, and /V.N/ sequences was highly sensitive to speaking rate and context, more so than on sequences comprising a vowel between two nasals. The percentage of nasalance was often higher as speaking rate increased and in unstressed vowels vs. stressed vowels at a fast speaking rate. As for context, the percentage of nasalance was also higher if the nasal belonged to the same syllable as the target vowel and if it appeared in syllable coda position. Conversely, in /NVN/ sequences the percentages of nasality and nasalance were not affected by variations in speaking rate.

In any event, a vowel adjacent to a nasal in any syllable position - and particularly if uttered between two nasals - will increase in its degree of nasalization as compared to an oral vowel. The difference in the percentage of nasality between stressed and unstressed vowels is sometimes significant for vowels followed by a nasal, whether in the same syllable or not. Therefore, stress position does not seem to be as relevant to nasalization as is speaking rate, for which speakers use various strategies.

The findings from this study might be worth considering as reference information in order to conduct clinical studies on nasality disorders. The results from this study might also be relevant to the learning-teaching process of second languages, although additional research on nasalization with larger groups of normal-speaking participants is still needed. To conclude, the contextual variability found in this study illustrates the complex nature of the speech production mechanism and calls for further theoretical and experimental work. 


\section{Acknowledgements}

I would like to thank my colleagues for their insightful comments on an early draft of this paper, in alphabetical order: Ramón Cerdà Massó, Natàlia Fullana Rivera, Victoria Marrero Aguiar, Eugenio Martínez Celdrán, Xosé Luis Regueira Fernández, and Paolo Roseano.

\section{References}

ANDERSON, Raquel T., 1996: "Nasometric values for normal Spanish-speaking females: a preliminary report”, The Cleft Palate-Craniofacial Journal 33 (4), 333-336.

Baken, Ronald J., \& Robert F. OrLIKoff, 2000: Clinical Measurement of Speech and Voice, San Diego: Singular Publishing Group.

BEDDOR, Patrice S., 2007: "Nasals and nasalization: the relation between segmental and coarticulatory timing" in Jürgen Trouvain \& William J. BARRY (eds.): Proceedings of the 16th International Congress of Phonetic Sciences, Saarbrücken, 249-254.

BelL-BeRTI, Fredericka, \& Hajime HiRose, 1973: "Patterns of palatoglossus activities and their implications for speech organization", Haskins Laboratories Status Report on Speech Research SR-34, 203-209.

BelL-BeRTI, Fredericka, 1973: The velopharyngeal mechanism: an electromyographic study, Haskins Laboratories Status Report on Speech Research, Supplement.

BelL-Bert1, Fredericka, 1976: "An electromyographic study of velopharyngeal function in speech", Journal of Speech and Hearing Research 19, 225-240.

BELL-BERTI, Fredericka, 1993: "Understanding velic motor control: studies of segmental context" in Marie K. Huffman \& Rena A. Krakow (eds.): Phonetics and Phonology 5: Nasals, Nasalization and the Velum, San Diego: Academic Pres, 63-85.

Bell-Berti, Fredericka, Thomas Baer, Katherine S. Harris \& Seiji NiImI, 1979: "Coarticulatory effects of vowel quality on velar function", Phonetica 36, 187-193.

BelL-Bert1, Fredericka, \& Katherine S. HaRRIS, 1981: "A temporal model of speech production", Phonetica 38, 9-20.

Bell-BeRT1, Fredericka, \& Rena A. KRAKow, 1991: "Anticipatory velar lowering: A coproduction aCcount", Journal of the Acoustical Society of America 90, 112-123. 
Brunnegard, Karin, \& Jan van Doorn, 2009: "Normative data on nasalance scores for swedish as measured on the Nasometer: Influence of dialect, gender, and age", Clinical Linguistics and Phonetics 23 (1), 58-69.

ChafCouloff, Michel, \& Alain MarChal, 1999: "Velopharyngeal coarticulation” in Willam J. HardCAStLe \& Nigel Hewlett (eds.): Coarticulation. Theory, data and techniques, Cambridge: Cambridge University Press, 69-79.

ClumeCK, Harold, 1976: "Patterns of soft palate movements in six languages", Journal of Phonetics 4, 337-351.

Delvaux, Véronique, Didier Demolin, Bernard Harmegnies \& Alain Soquet, 2008: "The aerodynamics of nasalization in French", Journal of Phonetics 36, 578-606.

Engwall, Olof, Véronique Delvaux \& Thierry Metens, 2006: "Interspeaker variation in the articulation of nasal vowels", Proceedings of the 7th ISSP, 3-10.

Farnetani, Edda, 1999: "Coarticulation and connected Speech Processes" in William J. Hardcastle \& John LAVER (eds.): The Handbook of Phonetic Sciences, Oxford: Blackwell Publishing, 371-404.

Farnetani, Edda, \& Daniel ReCAsens, 1999: "Coarticulation models in recent speech production theories" in William J. Hardcastle \& Nigel Hewlett (eds.): Coarticulation, Cambridge: Cambridge University Press, 31-65.

FleGE, James E., 1988: "Anticipatory and Carry-Over Nasal Coarticulation in the Speech of Children and Adults", Journal of Speech and Hearing Research 31, 525-536.

Fletcher, Samuel G., 1970: "Theory and instrumentation for quantitative measurement of nasality”, The Cleft Palate-Craniofacial Journal 7, 601-109.

Fletcher, Samuel G., \& Sharon D. Frost, 1974: "Quantitative and graphic analysis of prosthetic treatment for 'nasalance'”, The Journal of Prosthetic Dentistry 32 (3), 284-291.

Fowler, Carol A., 1980: "Coarticulation and theories of extrinsic timing", Journal of Phonetics 8, 113-133.

HaApanen, Marja-Leena, 1991: "Nasalance scores in normal Finnish speech", Folia Phoniatrica et Logopaedica 43 (4), 197-203.

HAJEK, John, 1997: Universals of sound change in nasalization, Oxford: Blackwell Publishers. 
Hirschberg, Jeno, Szilvia Bok, Márta Juhasz, Zsuzsa Trenovszki, Péter Votisky \& Andor Hirschberg, 2006: "Adaptation of nasometry to Hungarian language and experiences with its clinical application", International Journal of Pediatric Otorhinolaryngology 70, 785-798.

Kavanagh, Maru Lou, E. Jane Fee, Joseph Kalinowski, Philip C. Doyle \& Herbert A. Leeper, 1994: "Nasometric values for three dialectal groups within the Atlantic provinces of Canada", Journal of Speech-Language Pathology and Audiology 18, 7-13.

Kay Elemetrics C., 2004: Computerized Speech Lab (CSL) Models 4500/4150: Installation, Instruction and Maintenance Manual, NJ: Kay Elemetrics.

Kay Elemetrics C., 2001: NasometerTM II Models 6400/6402: Installation/Instruction manual, NJ: Kay Elemetrics.

Kollia, Betty H., Vincent L. Gracco \& Katherine S. HaRRIS, 1995: "Articulatory organization of mandibular, labial, and velar movements during speech", Journal of the Acoustical Society of America 98 (3), 1313-1324.

Krakow, Rena A., 1993: "Nonsegmental influences on velum movement patterns: syllables, sentences, stress, and speaking rate", Haskins Laboratories Status Report on Speech Research, 31-48.

KueHn, David P., \& Jerald B. Moon, 1998: "Velopharyngeal closure force and levator veli palatini activation levels in varying phonetic contexts", Journal of Speech, Language, and Hearing Research 41, 51-62.

Ladefoged, Peter, \& Ian Maddieson, 1996: The sounds of the world's languages, Oxford: Blackwell.

Leeper, Herbert A., Anne P. Rochet \& Ian Mackay, 1992: "Characteristics of nasalance in Canadian speakers of English and French" in Proceedings of the International Conference on Spoken Language Processing, Alberta: Banff, 49-52.

Litzaw, Laura L., \& Rodger M. DaLston, 1992: "The effect of gender upon nasalance scores among normal adult speakers", The Journal of Communication Disorders 25, 55-64.

Marchal, Alain, 2009: From Speech Physiology to Linguistic Phonetics, London: Iste Ltd.

Mattıolı, Raimundo G., 2007: Medidas de nasalância em crianças com fissura labiolapatina e fala normal. Tesis de maestría, Universidade de Sao Paulo.

Mira Mateus, Maria Helena, \& Ernesto D’Andrade, 2000: The phonology of Portuguese, Oxford: Oxford University Press. 
Mishima, Katsuaki, Asuka Sugll, Tomohiro Yamada Hideto Imura \& Toshio Sugahara, 2008: "Dialectal and gender differences in nasalance scores in a Japanese population", Journal of Craniomaxillofacial Surgery 36, 8-10.

Moll, Kenneth L., \& Raymond G. Daniloff, 1971: "Investigation of the timing of velar movements during speech", Journal of the Acoustical Society of America 50, 678-684.

Montagu, Julie, 2007: "Temporal extent of nasalization relative to the tongue articulation in French nasalized vowels", Proceedings of the International Conference of Phonetic Sciences.

Morais Barbosa, Jorge, 1962: "Les voyelles nasales portugaises: interprétation phonologique" in Proceedings of the IVth International Congress of Phonetic Sciences, La Haya: Mouton, 691-708.

MunhalL, Kevin, \& Anders LöFQvist, 1992: "Gestural aggregation in speech: Laryngeal gestures", Journal of Phonetics 20, 111-126.

Navarro Tomás, Tomás, 1985²2 [1918]: Manual de pronunciación española, Madrid: CSIC.

Nichols, Alan C., 1999: "Nasalance statistics for two Mexican populations”, The Cleft Palate-Craniofacial Journal 36, 57-63.

Obediente, Enrique, 2007: Fonética y fonología, Mérida: Universidad de Los Andes, Consejo de Publicaciones.

Ohman, John J., 1976: "A model of speech aerodynamics", Report of the Phonology Laboratory Berkeley 1, 93-107.

Ohman, John J., \& Manhari Ohala, 1993: “The phonetics of nasal phonology: Theorems and data” in M. K. Huffman \& A. Rena(eds.): Nasals, Nasalization and the Velum, San Diego: Academic Press, 225-249.

Ohman, Sven E. G., 1966: "Coarticulation in VCV utterances. Spectrographic Measurements", Journal of the Acoustical Society of America 39, 151-168.

Prathanee, Benjamas, Sanguansak Thanaviratananich, Amornrat Pongjunyakul \& Kanda RengpatanakiJ, 2003: "Nasalance scores for speech in normal Thai children", Scandinavian Journal of Plastic and Reconstructive Surgery and Hand Surgery 37, 351-355.

Reetz, Henning, \& Allard Jongman, 2008: Phonetics: transcription, production, acoustics, and perception, Oxford: Wiley-Blackwell.

Regueira, Xosé Luis, 2010: “Nasalización en gallego y en portugués”, Estudios de fonética experimental XIX, 71-110. 
Rochet, Anne Putnam, Bernard L. Rochet, Elisabeth A. Sovis \& Dallyce L. Mielke, 1998: "Characteristics of nasalance in speakers of western Canadian English and French", Journal of Speech-Language Pathology and Audiology 22 (2), 94-103.

Rossato, Solange, Pierre Badin \& Florence Bouaouni, 2003: "Velar movements in French: An articulatory and acoustical analysis of coarticulation" in Proceedings of the 15th linternational Conference of Phonetic Sciences, 3141-3144

Ruhlen, Merritt, 1975: "Patterning of nasal vowels" in Nasalfest. Papers from a Symposium on Nasals and Nasalization, 175-196.

Saltzman, Elliot L., \& Kevin G. Munhall, 1989: "A dynamical approach to gestural patterning in speech production”, Ecological Psychology 1, 333-382.

Seaver, Earl J., Rodger M. Dalston, Herbert A. Leeper \& Larrry E. Adams, 1991: "A study of nasometric values for normal nasal resonance", The Journal of Speech and Hearing Research 34, 715-721.

SolÉ, Maria Josep, 1995: "Spatio-temporal pattern of velopharyngeal action in phonetic and phonological nasalization”, Language and Speech 38 (1), 1-23.

SolÉ, Maria Josep, 2007: "Compatibility of features and phonetic content. The case of nasalization" in Proceedings of XVIth the International Conference of Phonetic Sciences, 261-266.

Solé, Maria Josep, \& John J. Ohala, 1991: "Differentiating between phonetic and phonological processes: the case of nasalization" in Proceedings of the XIIth International Congress of Phonetic Sciences, 110-113.

Stevens, Kenneth N., 1998: Acoustic Phonetics, Cambridge, MA: The MIT Press.

SWeEney, Triona, Debbie Sell \& Myra O’Regan, 2004: "Nasalance scores for normal-speaking Irish children", The Cleft Palate-Craniofacial Journal 41, 168-174.

Tachimura, Takashi, Chihiro Mori, So-ichiro HiRata \& Takeshi WadA, 2000: "Nasalance score variation in normal adult Japanese speakers of mid-west Japanese dialect", The Cleft Palate-Craniofacial Journal 37, 463-467.

Van Doorn, Jan, \& Alison Purcell, 1998: "Nasalance levels in the speech of normal Australian children", The Cleft Palate-Craniofacial Journal 35, 287-292.

Van Lierde, Kristiane M. M., Floris L. Wuyts, Marc de Bodt \& Paul van Caumenberge, 2001: "Nasometric values for normal nasal resonance in the speech of young Flemish adults", The Cleft Palate-Craniofacial Journal 38, 112-118. 
Van Lierde, Kristiane M., John van Borsel, Mieke Moerman \& Paul van Caumenberge, 2002: "Nasalance, nasality, voice, and articulation after uvulopalatopharyngoplasty”, Laryngoscope 112 (5), 873-878.

Van Lierde, Kristiane M., Floris L. Wuyts, Marc de Bodt \& Paul van Cauwenberge, 2003: "Age-related patterns of nasal resonance in normal Flemish children and young adults", Scandinavian Journal of Plastic and Reconstrive Surgery and Hand Surgey 37, 344-350.

Whitehill, Tara L., 2001: "Nasalance measures in Cantonese-speaking women”, The Cleft Palate-Craniofacial Journal 38, 119-125.

ZajaC, David J., Robert Mayo \& Ryuta Kataoka, 1998: "Nasal Coarticulation in Normal Speakers. A Re-Examination of the Effects of Gender", Journal of Speech, Language, and Hearing Research 41, 503-510. 